\title{
On Evaluation of Costume Brand Communication
}

\author{
Jie Yang \\ School of Art \\ Hainan University, \\ Haikou 570228, China \\ 894544081@qq.com
}

\begin{abstract}
This essay aims to explore how to evaluate the effect of costume brand communication. The author concludes that evaluating the effect of brands communication through three aspects--the market environment, brands performance and consumers' mindset-- is a relatively passive mode. The pro-active concept is to evaluate the communication effect before and while the plan is carried out in order to adjust and improve the communication plan dynamically. The effective evaluation of communication should be result-oriented, but this doesn't mean to cater to consumers like water. On the contrary, to measure consumers is to shape them more effectively.
\end{abstract}

Keyword-Costume Brand; Communication Effect; Effect Evaluation; Mode

\section{INTRODUCTION}

Amid the increasing complexity and changes in the costume consumer market, costume brand, which can help save the time for making purchase decisions and lower the consumption risks, becomes the common pursuit for businesses and consumers. For costume enterprises, the brand can enhance the consumer's awareness of the products, as well as create more marg inal benefits, thus building the line of defense for competition. Brand communication serves as a bridge to connect the market and enterprises, as well as a bridge of strategy for the costume brand to go to the future. Brand communication is not a random act; costume enterprises try to change the awareness, attitudes, emotions and behaviors of consumers through brand communication, while whether this change has met the expectation is the an important index for measuring the brand communication. From a microscopic point of view, the communication effect is affected by factors such as the communicator, the content, source, context of communication and the consumers themselves. From a macroscopic point of view, it is profoundly affected by economic situation, consumption culture and political environment. Thus the production of effect of brand communication is a complex social process.

\section{TRADITIONAL MODE OF EFFECT EVALUATION}

Communication effect is one of the major categories in communication studies. It refers to the extent of realization of the purpose or intention of the communicator, which is reflected in the awareness, attitudes, emotions and behaviors of the receivers. Like feeling the pulse, excellent effect evaluation can rapidly and accurately evaluate the health conditions of the brand communication activities and provide support for making decision in improving the communication.

There are many ways to evaluate the effect of brand communication, the most common of which is the cost approach. In this approach, the brand communication effect is identified by using the current replacement cost of the brand minus depreciation. The calculation formula is: brand communication effect=brand replacement cost-depreciation for losing efficacy-functional depreciation-economic depreciation. In fact, there is great deficiency with this approach. There is no direct causal connection between the effect and cost of the brand communication and it has considered the changes in the market price.

Table 1: Traditional Indexes for Evaluating the Brand Communication Effect

\begin{tabular}{|l|l|l|}
\hline Market environment & $\begin{array}{l}\text { Brand } \\
\text { performance }\end{array}$ & Consumer mindset \\
\hline Market scale & Brand premium & Awareness \\
\hline Growth potential & Price elasticity & Knowledge \\
\hline Risk profile & Market share & Preference \\
\hline $\begin{array}{l}\text { Competition } \\
\text { response }\end{array}$ & Cost structure & Loyalty \\
\hline Media behavior & $\begin{array}{l}\text { Expansion } \\
\text { capacity }\end{array}$ & Behavior \\
\hline
\end{tabular}


The second method to evaluate the effect of brand communication is the market approach, which directly reflects the market changes by evaluating the communication effect based on the current market price. The calculation formula is: brand communication effect=effect of transfer of communication activities for reference-(the difference between the effect of communication evaluated and the effect of communication of the band for reference). It is hard to directly apply the market method in the actual operation, since it is hard to find similar communication activities as object of reference due to the unique feature of brand communication. David A. Aaker 1 believes that the evaluation method based on market situation cannot reflect the communication effect in a good way, and the consumer's attitude should be measured thoroughly. He also includes brand loyalty, perceived brand quality, brand associations and brand awareness in the system of evaluation of brand communication effect. According to Young \& Rubicam2, the brand strength and brand stature should be considered, in which brand strength is determined by the combination of brand differentiation and relevance, and brand stature, the combination of brand esteem and knowledge.

According to the World Brand Lab3, there is no model that can evaluate the communication effect in just one time. It needs to track the effect of brand communication through several evaluation standards in a systematic and dynamic manner. The standards should include the consumer perception, market effect, brand value and impact on clients. In other words, the costume brand communication involves several links in the costume manufacturing and marketing, thus bringing difficulties for the communication effect evaluation. Don E.Schultz and others puts forward the concept of integrated marketing communication, offering a brand new perspective and approach for communication effect evaluation. They believe that brand communication goes beyond the category of communication between costume brand and consumers, and runs through the relationship of communications with consumers from the product, packaging, promotion, exhibition to advertising, after-sale services and public relations.4 It is thus clear that the communication effect evaluation is a real-time dynamic and deepening process. In the new media era, integrated marketing communication is still booming.

\section{A NEW APPROACH IN THE EFFECT EVALUATION}

Brand communication effect is a mediating factor between the communication activities and consumers. In fierce market competition, you will be unable to establish the current brand image and value without properly evaluating the effect of communication activities of the current brand, and the follow-up actions will be in vain. In the new media era, the communication effect evaluation is transcending the traditional ex-post evaluation and is evolving into the mode of combination of ex-ante evaluation, (real-time monitoring) interim evaluation and ex-post evaluation (the traditional mode).

The social media and big data provide motivation and guarantee for the real-time dialogue between the brand communicator and the consumer-the verbal communications and emotional exchanges, and the real-time emerging communication hot spots require the communicator to immediately adjust the communication plan. Thus the brand communicator will put more emphasis on the consumer the communication effect and the brand communication enters a spiral fast lane with immediate evaluation and immediate adjustment. Therefore, the author of this paper believes that the proactive approach of effect evaluation should be adopted. That is, to predict the brand communication effect before the communication activities are carried out, and to proactively improve the communication plan accordingly and try to enhance the consumer's receptiveness of the communication activities. Only in this way can the operation of the system of costume brand communication be more effective.

The "proactive" effect evaluation is built on the basis of ex-ante evaluation of communication activities. The author believes that in the media era, researchers can evaluate the five major indexes from the following five steps:

\footnotetext{
' Shi Kehao. Evaluation of Brand Equity Based on the Brand Loyalty[J]. China Business \& Trade, 2013,24.

2 Zhao Long. On Credibility-oriented Evaluation System of Brand Value [J]. Modern Communication (Journal of Communication University of China), 2014,08:107-111.

3 Yuan Zeming, Ma Yu. AComparative Study on the Chinese and

Foreign Brand Evaluation [J]. Modern Finance and Economics-Journal Tianjin University of Finance and Economics, 2008,03:73-78.

${ }^{4}$ Liu Qiang. On the Effect of Brand Communication[J]. Modern Marketing,2011,05:54-55.
} 


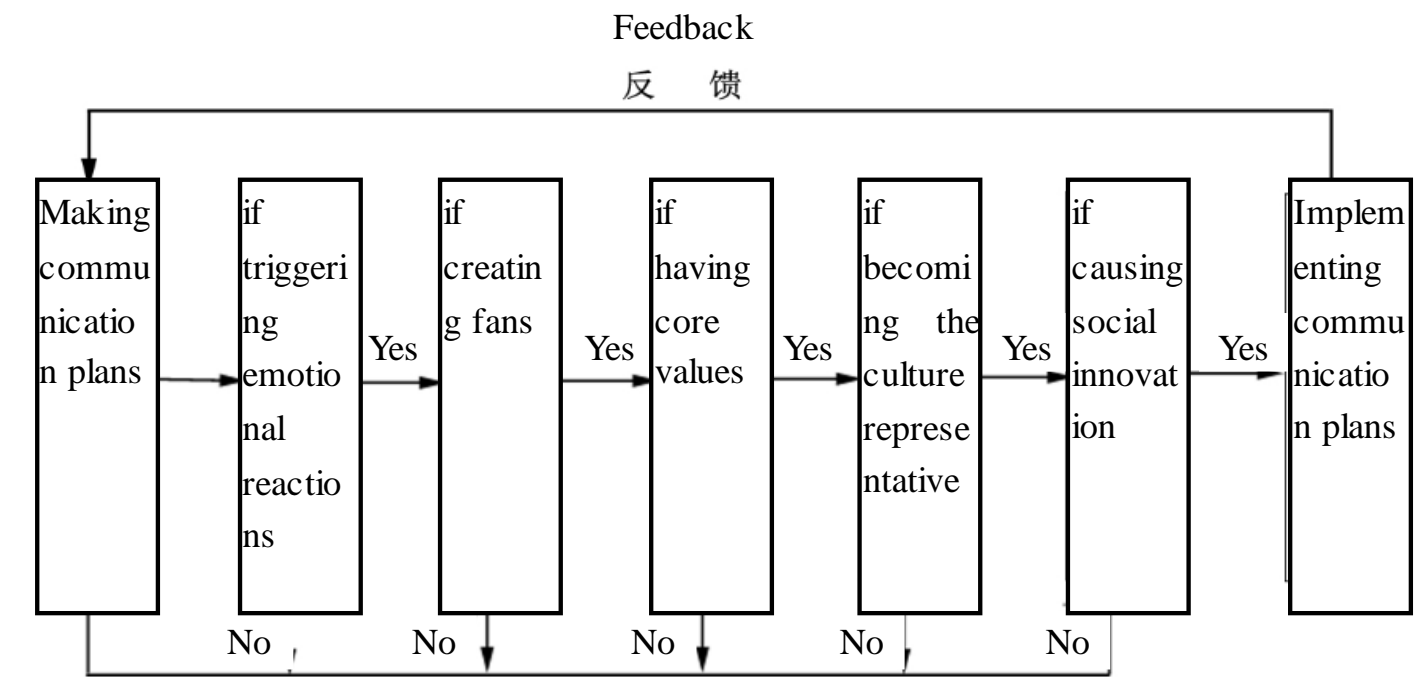

Figure 1. Process of Ex-ante Evaluation of Communication Activities

\section{A. Index 1: if triggering strong emotional reactions}

High quality is the foundation of costume brands to remain in an invincible position in the market competition. The emotional projection should be a powerful weapon in the market expansion. Like being in love, brand communication conveys certain emotional feelings to consumers, inspiring their love and loyalty to the brand. The charm of brand lies in establishing certain emotional connections with consumers.

Stories have become daily necessities for modern people, instead of just a hobby. "Telling a story to consumers" is no longer just the motto of experts on public opinion guidance and crisis management; it has also become the trump card for brand communication. In other words, brand communication means telling a dramatic story with empathy. The brand communicators should list all the emotional reactions of consumers made while listening, both positive and negative. Then they should try to arouse the positive emotions while prohibiting the negative ones.

According to the third person effect theory, the consumers tend to overestimate the influence that brand communications have on the behavior of others, and underestimate that on themselves. For example, the buyers of children's garment are their parents, but the advertisements of these garments are usually broadcast during the children's programs. Children, as the ostensible audience, do not have purchasing power; the brand communications reach the purpose of promotion through the influence of children on their parents. To realize the purpose of controlling the behavior of the consumers by affecting the ostensible audience is one of the fundamental ways of brand communication.

\section{B. Index 2: if creating fans}

Although fans are just a small part of the target consumers, they are most passionate and can be integrated into the brand communications. The brand communications do not just have a short-term impact; rather, it is a long-term process which is gradual and imperceptible. An important prerequisite for the smooth brand communications is that the brand and consumers share common interconnected space. Actually, consumers want to establish relations with other people, not the brand. Whether consumers like the brand is not important; what matters is what social opportunities and conveniences the costume brand can provide for consumers.

Some businesses are afraid of receiving negative feedback. However, the author believes that if you want to cultivate fans, you should not be fearful of the negative news, especially those without many strong bad implications. Negative feedback is just the rebound in basketball - although you as long as you seize it, you will have endless opportunities. Receiving negative feedback means you have one more opportunity to communicate with consumers and every contact with consumers may promote the brand communication. As a matter of fact, for consumers, negative news about the brand is just like the vaccine, which can give them strong resistance against the negative publicity about the brand and help safeguard the brand image.

To cultivate fans, just relying on the communication is not enough; you need to create opportunities for the participation of the consumers. Anita Elberse, professor at Harvard Business School, points out in her book Blockbusters: Hit-making, Risk-taking, and the Big Business of Entertainment that human beings are sociable in nature and like to emulate those better than themselves, and that is why there are so many popular songs, blockbusters and bestsellers5. For Ice Bucket Challenge, the key to its global popularity lies in the game, not charity. How to provide interesting and challenging experience for the participating consumers has become a compulsory course for the costume brand communicators.

\footnotetext{
5 Anita Elberse, Blockbusters: Hit-making, Risk-taking, and the Big Business of Entertainment[M], Brilliance Audio, April 15, 2014.
} 


\section{Index 3: if having particularcore values}

If claiming to be excellent in all aspects, then most of the brands will fail to have impact on even a single person. In successful brand communications, they just focus on conveying the only particular information to attract the attention of target consumers. MUJI's simple design, Levi's jeans and Cartier's noble style-to a great extent, the reason for these brands to capture people's eyes is that they have built up unique values and distinctive personality. The role that the brand identity system plays is self-evident. According to the sleeper effect, over time, the effect of the credibility of the source will decrease or disappear, while the persuasiveness of the content itself will fully appear. Thus designing the brand concept is an important prerequisite for the brand communication and whether the brand value can last long is determined by the vitality of the concept of the costume.

\section{Index 4: if becoming the culture representative}

Brand is one of the identities of the followers, reflecting their idea and pursuit and symbolizing their identity and status. Brand communication is meant to enable the consumers to express their mind to the world through the medium of the costume. Products are never mentioned in Nike's brand communication. Then how does it do it? Nike shows its esteem for the great athletes and sports, in order to show that Nike is the representative of sports culture in the digital content, Nike develops Nike+, the most popular application which can record the route and time of sports and connect the runners and coaches with similar interests together, encouraging them to provide feedback and share with their friends on social network. According to AISAS model6, sharing is the key to social popularity. It not only delivers the information about costume consumption, but also helps form the social norm in costume consumption.

Brand communication endows the product with certain meanings through selection and combination of information. An attractive brand must be a brand that can be explained in just one sentence. It must be a brand with unique features to remember and even the small details can reflect its core value. Whether the costume concept is unique, can convey the value and ca become the culture representative of social behavior is one of the key points for consideration in designing the communication strategy.

\section{E. Index 5: if causing social innovation}

In brand building, researchers must foster new trends as the first group of people accepting the brand will bring more people in the consumption of new products with their first use. In a large extent, these people can help the brand communicators finish most of the work of promotion, and attract other consumers into this social innovation. The key for the brand to leading in the innovation in consumption lies in whether the brand communication can arouse and attract those consumers that like to try new things.

\footnotetext{
6 AISAS is a new model of analysis of consumers' behavior in light of the changes in the life of consumers in the era of internet and wireless applications, which is: Attention-Interest-Search-Action-Share.
}

Since 1990s, Theory of New York has become an active advocate of the "wearable" career women's apparel. Today, being "wearable" has long become part of features of the career women's apparel, whose designers have abandoned the past symbolic design. It's fair to say that the career apparel has broken the limit of regular thinking of consumers and triggered revolutionary thinking, bringing fashions of seeking success and independence for urban women. Now the career women of Theory have been endowed with more elements of freedom, interest and politics. Every new product launch brings impact on the mind of the people and even arouses the criticism of the media. Actually, it is just this capacity of public opinion building that enables Theory to lead in the revolution in career women's apparel.

\section{CONCLUSIONS}

In actual cases, the proactive effect evaluation is a rapid response process, which aims to cultivate and lead market needs. Promoted by the social media and big data, the focus of costume brand communication has changed to making rapid adjustment according to the ex-ante evaluation and real-time monitoring, and integrating the brand information and brand spirit into every links in brand communication, thus effectively restraining the brand interpretation beyond expectation. For this purpose, researchers need to monitor the communication activities in various channels in the same period of time, pay attention to coordinating the choice of time for the release and pace of operation, trying to make biological, not mechanical, integration of the communication activities.

Brand building takes a long time. In this process, even a careless mistake can destroy the positive knowledge and emotional accumulation of consumers about the brand. Thus it is very important to conduct real-time monitoring of the communication effect. What needs to be reminded is that the behavior of evaluation may distort the results. For example, with certain anticipation, the people who conduct the evaluation may affect the evaluation steps in a unconscious way, or misinterpret some data in order to meet their anticipation. Of course, the consumer-centered proactive effect evaluation doesn't mean to cater to consumers like water. On the contrary, to measure consumers is to shape them more effectively.

\section{REFERENCES}

[1] Bi Yantao (Ed). Brand Building[M]. Beijing: Central Compilation \& Translation Press, 2012

[2] Guo Qingguang. Introduction to Communication [M]. Beijing: China Renmin University Press (2ndEdition), 2011

[3] Don E.Schultz, Heidi Schultz. Integrated Marketing Communication [M]. He Xijun Trans. Beijing: China Financial \& Economic Publishing House, 2005

[4] Michael A Hitt et al. Strategic Management [M]. Xue Youzhi et al Trans. Beijing: China Machine Press, 2010

[5] Kotler P., Keller K.L. Marketing Management [M]. Wang Yonggui et al Trans. Shanghai: Truth \& Wisdom Press, 2009

[6] Xu Jing. The Comprehensive Shaping and Spread of Fashion Brand [M]. Shanghai: Donghua University Press, 2010

[7] Toby Meadows. How to Set up \& Run a Fashion Label [M]. Du Binging Trans. Beijing: China Textile \& Apparel Press, 2010

[8] Cao Wen. "A Study on the Brand Communication from the Perspective of Int egrated Marketing Communication" [D]. Jiangxi University of Finance and Economics, 2010 
[9] Li Baixin. "On the Corporate Brand Communication Based on the Theory of Diffusion of Innovation"[D].Wuhan University of Science and Technology, 2009
[10] Huang Yushui. "A Study on the Luxury Brand Communication" [D]. Zhejiang University, 2011

[11] Wei Xiaojuan. "On the Costume Brand Communication"[D]. Tianjin Polytechnic University, 200. 